medRxiv preprint doi: https://doi.org/10.1101/2022.01.22.22269691; this version posted February 22, 2022. The copyright holder for this preprint

(which was not certified by peer review) is the author/funder, who has granted medRxiv a license to display the preprint in perpetuity.

This article is a US Government work. It is not subject to copyright under 17 USC 105 and is also made available for use under a CCO license.

$02 / 20 / 2022$

\title{
BASELINE METABOLIC PROFILING AND RISK OF DEATH FROM COVID-19
}

\author{
Glen H. Murata, MD* \\ Allison E. Murata, MSIM^ \\ Heather M. Campbell, PharmD, $\mathrm{PhD}^{\wedge \&}$ \\ Brent Wagner, MD*\# \\ Benjamin H. Mcmahon, $\mathrm{PhD}^{\%}$ \\ Jenny T. Mao, MD, FCCP*\#
}

* New Mexico VA Health Care System, Albuquerque NM

^ VA Cooperative Studies Program - Clinical Research Pharmacy Coordinating Center, Albuquerque NM

\& University of New Mexico College of Pharmacy, Albuquerque NM

\# University of New Mexico School of Medicine, Albuquerque NM

$\%$ Los Alamos National Laboratory, Los Alamos NM 
medRxiv preprint doi: https://doi.org/10.1101/2022.01.22.22269691; this version posted February 22, 2022. The copyright holder for this preprint

(which was not certified by peer review) is the author/funder, who has granted medRxiv a license to display the preprint in perpetuity.

This article is a US Government work. It is not subject to copyright under 17 USC 105 and is also made available for use under a CCO license.

METABOLIC PROFILING AND COVID-19 DEATH

\section{ABSTRACT}

Objective: To derive a predicted probability of death (PDeathLabs) based upon complete value sets for 11 clinical measurements (CM) obtained on patients prior to their diagnosis of coronavirus disease (COVID-19). PDeathLabs is intended for use as a summary metric for baseline metabolic status in multivariate models for COVID-19 death.

Methods: Cases were identified through the COVID-19 Shared Data Resource (CSDR) of the Department of Veterans Affairs. The diagnosis required at least one positive nucleic acid amplification test (NAAT). The primary outcome was death within 60 days of the first positive test. We retrieved all values for systolic blood pressure (SBP), diastolic blood pressure (DBP), oxygen saturation (O2SAT), body mass index (BMI), estimated glomerular filtration rate (EGFR), alanine aminotransferase (ALT), serum albumin (ALB), hematocrit (HCT), LDL cholesterol (LDL) hemoglobin A1c (A1C), and HDL cholesterol (HDL) if they were done at least 14 days prior to the NAAT. Clinicians evaluate several attributes of CM that are of critical importance: metabolic control, disease burden, chronicity, refractoriness, tendency to relapse, temporal trends, and lability. We derived 1-3 parameters for each of these attributes: the most recent value (metabolic control); time-weighted average and abnormal area under a severity versus time curve (disease burden); time and number of readings above or below goal (chronicity); longest abnormal cluster and time/number of consecutive readings above goal if the last value was abnormal (refractoriness); number of abnormal clusters (tendency to relapse); long- and short-term changes (temporal trends); and coefficient of variation and mean deviation between consecutive readings (lability). We created computer programs to derive cumulative values for these 13 parameters for all $11 \mathrm{CM}$ as each new value is added. A fitted logistic model was developed for each $\mathrm{CM}$ to determine which of the 13 parameters contributed to the risk of death. A main logistic model was developed to determine which of the $13 \times 11=143$ metabolic parameters were independently predictive of death. The resulting model was used to derive PDeathLabs for each patient and the area under its receiver operating characteristic 
medRxiv preprint doi: https://doi.org/10.1101/2022.01.22.22269691; this version posted February 22, 2022. The copyright holder for this preprint

(which was not certified by peer review) is the author/funder, who has granted medRxiv a license to display the preprint in perpetuity.

This article is a US Government work. It is not subject to copyright under 17 USC 105 and is also made available for use under a CCO license.

METABOLIC PROFILING AND COVID-19 DEATH

(ROC) curve calculated. Single variable logistic models were also derived for age at diagnosis, the Charlson 2-year (Charl2Yr) and lifetime (CharlEver) scores, and the Elixhauser 2-year (Elix2Yrs) and lifetime (ElixEver) scores. Stata was used to compare the ROCs for PDeathDx and each of the other metrics.

Results: On September 30, 2021, there were 347,220 COVID-19 patients in the CSDR. 329,491 (94.9\%) patients had CM performed at least 14 days prior to the COVID-19 diagnosis and form the basis for this report. 17,934 (5.44\%) died within 60 days of the diagnosis. On the subset regressions, the number of significant parameters ranged from all 13 for SBP to 7 for HDL. 239,393 patients had complete sets of data for developing the main model. Of 143 candidate predictors, 49 parameters were identified as statistically significant, independent predictors of death. The most influential domains were the most recent value, disease burden, temporal trends, and tendency to relapse. The ROC area for PDeathLabs was $0.785+/-0.002$. No difference was found in the ROC areas of PDeathLabs and age at diagnosis $(0.783+/-$ $0.002 ; \mathrm{P}=\mathrm{NS}$ ). However, the ROC area for PDeathLabs was significantly greater than that of Charl2Yrs (0.704+/- 0.002; $\mathrm{P}<0.001)$, CharlEver $(0.729+/-0.002 ; \mathrm{P}<0.001)$, Elix2Yrs $(0.675$ $\pm 0.002 ; \mathrm{P}<0.001)$, and ElixEver $(0.707+/-0.002 ; \mathrm{P}<0.001)$. A poor prognosis was found for chronic systolic hypertension. On the other hand, a higher BMI was protective once SBP, DBP, HDL, LDL and A1C were considered.

Conclusions: Our study confirms that parameters derived for $11 \mathrm{CM}$ are significant determinants of COVID-19 death. The most recent value should not be selected over other parameters for multivariate modeling unless there is a physiologic basis for doing so.

PDeathLabs has the same discriminating power as age at diagnosis and outperforms comorbidity indices as a summary metric for pre-existing conditions. If validated by others, this approach provides a robust approach to handling $\mathrm{CM}$ in multivariate models. 
medRxiv preprint doi: https://doi.org/10.1101/2022.01.22.22269691; this version posted February 22, 2022. The copyright holder for this preprint

(which was not certified by peer review) is the author/funder, who has granted medRxiv a license to display the preprint in perpetuity.

This article is a US Government work. It is not subject to copyright under 17 USC 105 and is also made available for use under a CCO license.

METABOLIC PROFILING AND COVID-19 DEATH

\section{INTRODUCTION}

Many mathematical models have been developed for predicting outcomes of COVID-19 infection (1-5). They have gained popularity because they are very useful for managing patients and allocating scarce resources. Most models are composed of demographic traits, comorbidity scores, and pre-existing conditions grouped under headings like "malignancy". Clinical measurements (CM) have not been prominent features of these models. CM provide valuable information about the metabolic status of patients at baseline and include vital signs and routine laboratory tests. Some models have none $(1,5)$, while others include only one (usually the most recent) of the hundreds of measurements that might be available for each type (2-4). However, there are convincing arguments to expand the use of CM in these prediction rules:

a) A diagnosis informs us that the patient has a certain disease, while CM tell us the burden imposed by its risk factors or the disease itself. The two are not synonymous. For example, one patient with hypertension might have had severely elevated blood pressures (BPs) for decades, while another might be normotensive because of successful treatment. The first would be considered at high risk while the second is "normal". On the other hand, a patient may not have been given the diagnosis of hypertension even though her BPs are abnormal for a term pregnancy. Classification errors such as these are very common in clinical practice.

b) $\mathrm{CM}$ provide some insight into the mechanism of injury. For example, suppose chronic hypoxia is more closely associated with death than acute hypoxia. This observation suggests that cumulative injury over time (such as with secondary pulmonary hypertension) is more influential than the acute metabolic burden imposed by low oxygen levels at presentation.

c) CM add explanatory variables to a prediction model. These components are critical for identifying targets for interventions to reduce the risk. For example, causality might be 
medRxiv preprint doi: https://doi.org/10.1101/2022.01.22.22269691; this version posted February 22, 2022. The copyright holder for this preprint

(which was not certified by peer review) is the author/funder, who has granted medRxiv a license to display the preprint in perpetuity.

This article is a US Government work. It is not subject to copyright under 17 USC 105 and is also made available for use under a CCO license.

METABOLIC PROFILING AND COVID-19 DEATH

inferred by a dose-response effect between the CM and risk of the death. The model

becomes "hypothesis-generating" and could lead to other studies confirming the

mechanism of injury or clinical trials to reduce the risk. Prediction rules rarely define

causality in a way that points to a further course of action.

$\mathrm{CM}$ are routinely included in periodic health examinations and available for testing in prediction models. They include systolic (SBP) and diastolic blood pressure (DBP), oxygen saturation level (O2Sat), body mass index (BMI), estimated glomerular filtration rate (EGFR), alanine aminotransferase (ALT), serum albumin (ALB), hematocrit (HCT), hemoglobin A1c (A1C), and low- (LDL) and high-density lipoprotein cholesterol (HDL). The major problem is the lack of a systematic approach to selecting the appropriate parameter for each type. There is no evidence that the most recent value of any type is the most influential measurement even though it is common practice to include them in models as a representative value. For example, if microvascular disease mediates the risk posed by diabetes, the most recent $A 1 c$ is the least suitable measure of tissue glycation. The purpose of this manuscript is to validate a method for summarizing the effects of hundreds of measurements done on each patient for each $\mathrm{CM}$ and to evaluate the effects of these parameters on prognosis.

Our approach emulates the way that clinicians interpret CM to reach conclusions about the patient's metabolic status. Unlike prediction rules, they rarely interpret individual values for CM out of context. In fact, conclusions are often based upon a review of neighboring values or even other domains of the medical record. Moreover, clinicians often render judgements about several attributes when assessing a CM. These attributes include metabolic control, chronicity, disease burden, temporal changes, refractoriness, tendency to relapse, and lability. Each concept is independent of the others and has clinical implications of its own. For example, a diabetic patient may have an $\mathrm{A} 1 \mathrm{C}$ that meets a metabolic target, but the entire value set could represent a substantial glycemic burden, indicate a tendency to relapse, and demonstrate a steep, upward trend. In our study, a parameter is a variable synthesized from the complete 
medRxiv preprint doi: https://doi.org/10.1101/2022.01.22.22269691; this version posted February 22, 2022. The copyright holder for this preprint

(which was not certified by peer review) is the author/funder, who has granted medRxiv a license to display the preprint in perpetuity.

This article is a US Government work. It is not subject to copyright under 17 USC 105 and is also made available for use under a CCO license.

METABOLIC PROFILING AND COVID-19 DEATH

value set for a $\mathrm{CM}$ that represents one attribute for that $\mathrm{CM}$. To reach conclusions about metabolic status requires extensive processing of all data for a $\mathrm{CM}$, deriving parameters for each attribute, and testing the association between derived parameters and COVID-19 death. Our computer programs not only derive these parameters but also generate a running summary whenever a new value is added to the set. Thus, the patient's status relative to any CM can be assessed in detail at any point in time.

\section{METHODS}

Cases were identified through VA's COVID-19 Shared Data Resource (CSDR). Membership in this registry requires at least one positive nucleic acid amplification test. The primary outcome was death within 60 days of the first positive result. The outcome was retrieved from the CSDR, which assigns a 1 to those who died and 0 otherwise. Data domains in the Corporate Data Warehouse (CDW) were interrogated for all measurements entered $\geq 14$ days before the diagnosis of COVID-19. This precaution excludes readings that may have been taken during the pre-symptomatic phases of illness. We retrieved SBP, DBP, O2Sat, heights and weights from the file Vital.VitalSign. The latter were used to calculate BMI. We also retrieved EGFR, ALB, HCT, ALT, A1C, HDL and LDL from the file Chem.PatientLabChem. The following parameters were derived for each of the $11 \mathrm{CMs}$ (above):

a) Metabolic control requires that the measurement be compared to an external standard; that both be standardized to a common scale; that the value is timely, that it has not already been treated, that enough time has elapsed since the last treatment change to reach a plateau value; and that it is not rapidly increasing or decreasing. Metabolic control is reflected in the most recent value (Value1). Our programs provide the option of raw or standardized values and require the user to specify a treatment target. They can be modified to exclude remote values but, for now, include all Value1s in the medical record regardless of their timeliness. No attempt was made to assess prior treatments. Temporal changes are handled separately (below). 
medRxiv preprint doi: https://doi.org/10.1101/2022.01.22.22269691; this version posted February 22, 2022. The copyright holder for this preprint

(which was not certified by peer review) is the author/funder, who has granted medRxiv a license to display the preprint in perpetuity.

This article is a US Government work. It is not subject to copyright under 17 USC 105 and is also made available for use under a CCO license.

METABOLIC PROFILING AND COVID-19 DEATH

b). Chronicity is defined as the total number of days or measurements above target. Each reading was paired with the preceding one. Days between successive abnormal readings were considered above goal; days between normal readings as at goal; days between a normal and abnormal reading as worsening; and days between an abnormal and normal reading as improving. Days above goal were summarized across all successive pairs in the patient's record (FUDaysAboveGoal). NumAboveGoal is the total number of measurements exceeding the target value in the patient's record.

c) Disease burden is the degree to which an abnormality has caused end-organ damage. For chronic diseases, it is almost always a function of severity and exposure time and expressed as the area under the severity $x$ time curve $(A U C)$. This concept applies to SBP, DBP, BMI, A1c, LDL and HDL. Our software uses a simple trapezoidal estimation technique without interpolation, extrapolation, or curve-fitting and includes all readings from the first to last value. AUC can be large just because the patient is elderly. To eliminate this possibility, our software derives AUC only above the target specified by the user (AbnAUC). Time-weighted averaging eliminates the sampling bias that arises from a tendency to measure a CM more frequently when it is abnormal. The raw average is an over-estimate of severity when abnormal readings are more closely spaced than normal ones. TimeWtAvg is defined as: AUC/(Total days of follow-up)

d) Refractoriness is the repeated failure to achieve goal and is represented by consecutive abnormal values (a "cluster"). Each cluster begins with a change from normal to abnormal value and terminates with the next normal value. The assumption is that an abnormal reading should have triggered an intervention that normalized the measurement. Refractoriness is worse when there are many readings in the cluster, or its duration is long. It can result from the failure to treat, failure of the patient to adhere, failure of the disease to respond, or intolerable side-effects. Our program defines the number of clusters for each patient (NumCluster) and a start date, consecutive days above goal (TimeAboveGoal), and consecutive readings above 
medRxiv preprint doi: https://doi.org/10.1101/2022.01.22.22269691; this version posted February 22, 2022. The copyright holder for this preprint

(which was not certified by peer review) is the author/funder, who has granted medRxiv a license to display the preprint in perpetuity.

This article is a US Government work. It is not subject to copyright under 17 USC 105 and is also made available for use under a CCO license.

METABOLIC PROFILING AND COVID-19 DEATH

goal (CtAboveGoal) for each cluster. The least refractory episode has a CtAboveGoal of one, and refractoriness increases as CtAboveGoal increases. TimeAboveGoal and CtAboveGoal are relevant only for patients with an abnormal $\mathrm{CM}$ at the time of COVID diagnosis. The term MaxClustDays refers to the longest cluster in the patient's medical record.

e) Relapses are the occurrence of abnormal values after being at goal. They can occur once or many times. Relapses are often caused by a steady progression in disease severity (like diabetes) which requires multiple titrations of treatment. The number of relapses is represented by NumCluster. The first abnormal cluster is given the value of one - i.e., the person has deteriorated from a previously normal state. Patients with a tendency to relapse have larger values for NumCluster. Relapse and refractoriness have different clinical implications. For example, a person can relapse many times, respond quickly to each intervention, and spend little time above goal. On the other hand, a person with refractoriness can have just one cluster that lasts for years.

f) Lability refers to variations in a CM from one reading to the next. Spontaneous variation can occur when the test is imprecise or when there are fluctuations in the $\mathrm{CM}$ itself. Test imprecision may be due to changes in conditions of testing (often behavioral) or variability in the assay. Results of these tests should be confirmed by repeated sampling. On the other hand, physiologic variability results from a complex interplay among multiple control mechanisms and is important in several conditions. For example, labile hypertension is a well-known clinical problem. It has also been shown that hypoglycemia in diabetes results from spontaneous variation in glucose levels and can only rarely be explained by patient behaviors. The coefficient of variation (CoeffVar) for each CM is derived from the grand mean (GrandMean) and standard deviation (GrandStD) for all values in the patient record and given by the expression GrandStD/GrandMean. MeanValDiff refers to the average of the absolute difference between all consecutive pairs. 
medRxiv preprint doi: https://doi.org/10.1101/2022.01.22.22269691; this version posted February 22, 2022. The copyright holder for this preprint

(which was not certified by peer review) is the author/funder, who has granted medRxiv a license to display the preprint in perpetuity.

This article is a US Government work. It is not subject to copyright under 17 USC 105 and is also made available for use under a CCO license.

METABOLIC PROFILING AND COVID-19 DEATH

g) Temporal trends refer to changes over time from one value to another and may be long- or short-term. NetChange is a measure of long-term trend and refers to the difference in the most recent and first value for each $\mathrm{CM}$. The software generates the mean of the 3 lagging values for each measurement (Lag3Mean). Lag3Dev refers to the fractional deviation of the current value from Lag3Mean and is given by the expression: (Value1 - Lag3Mean)/Lag3Mean.

Statistical methods - In summary, we analyzed the following 13 parameters for each CM: Value1, FUDaysAboveGoal, NumAboveGoal, AbnAUC, TimeWtAvg, NumClust, TimeAboveGoal, CtAboveGoal, MaxClustDays, CoeffVar, MeanValDiff, NetChange, and Lag3Dev. These values were extracted for each patient from the running summary associated with the most recent value. The default was to use all available readings in the medical record so that metabolic status was defined over the patient's lifetime.

Because there are 4 vital signs and 7 laboratory tests of interest, the list of covariates consists of $13 \times 11=143$ items. Group differences in categorical variables were tested by chisquare analysis. Group differences in continuous variables were analyzed by student's t-test and Mann-Whitney U-test. Because there were so many comparisons, univariate analysis is not included in this report but is available upon request.

For each CM, a subset logistic regression was done to identify which of the 13 parameters was predictive of death. A model was fitted to all patients with complete data. A variable was considered significant if the adjusted P-value associated with the coefficient was $<0.05$. The subset model was then used to assign a predicted probability of death to each patient. Receiver operating characteristic curve $(\mathrm{ROC})$ analysis was done to determine if that predicted probability discriminated between those who live and died.

All 143 variables were used to generate a main predictive model. Set-wise logistic regression was applied to all patients with a complete data set. The dependent variable was death within 60 days of diagnosis. Modeling started with the set of most recent values. Sets related to different criteria were added in succession, and previous variables were removed if 
medRxiv preprint doi: https://doi.org/10.1101/2022.01.22.22269691; this version posted February 22, 2022. The copyright holder for this preprint

(which was not certified by peer review) is the author/funder, who has granted medRxiv a license to display the preprint in perpetuity.

This article is a US Government work. It is not subject to copyright under 17 USC 105 and is also made available for use under a CCO license.

METABOLIC PROFILING AND COVID-19 DEATH

they became insignificant. A variable was considered significant if the adjusted P-value associated with its coefficient was $<0.05$. The final model was used to assign a predicted probability of death (PDeathLabs) to each patient based upon all CM. Again, ROC analysis was used to determine if PDeathLabs was able to identify those who died.

\section{RESULTS}

On September 30, 2021, there were 347,220 COVID-19 patients in VA's COVID-19 Shared Data Resource. Of these, 329,491 patients (94.9\%) had CM performed at least 14 days prior to the COVID-19 diagnosis and form the basis for this report. The mean age at the time of diagnosis was $59.1 \pm 16.6$ years; $85.5 \%$ were male; $23.4 \%$ were members of a racial minority; 9.2\% were Hispanic; $96.4 \%$ were veterans; $0.7 \%$ were on supplemental oxygen; and $12.2 \%$ were current smokers. $9.3 \%$ had been fully vaccinated at least 14 days prior to the COVID-19 diagnosis. $21.6 \%$ acquired their infections after July 1, 2021 and were presumed to have the delta variant. Overall, 17,934 patients (5.44\%) died within 60 days of their diagnosis.

Subset regressions were done for each $\mathrm{CM}$ to identify which of the 13 parameters were determinants of the outcome (Appendix). The model did not converge for ALT. As expected, single CM did not distinguish between surviving and dying patients very well, although some ROCs were close to those of co-morbidity scores. Nevertheless, the number of significant parameters ranged from all 13 for SBP to 7 for HDL. Value1 was significant for $7 \mathrm{CM}$, FUDaysAboveGoal for 9, NumAboveGoal for 9, AbnAUC for 9, TimeWtAvg for 9, NumClust for 10, TimeAboveGoal for 6, CtAboveGoal for 7, MaxClustDays for 5, CoeffVar for 10, MeanValDiff for 10, NetChange for 9, and Lag3Dev for 7.

239,393 patients (or $70.5 \%$ of the cohort) had complete sets of data for developing the main model. Table 1 shows the components of this model. Of 143 candidate predictors, 49 parameters were identified as statistically significant and independent predictors of death. The most influential domains were the most recent value, disease burden, temporal trends, and tendency to relapse. The main model was used to calculate a predicted probability of death 
medRxiv preprint doi: https://doi.org/10.1101/2022.01.22.22269691; this version posted February 22, 2022. The copyright holder for this preprint

(which was not certified by peer review) is the author/funder, who has granted medRxiv a license to display the preprint in perpetuity.

This article is a US Government work. It is not subject to copyright under 17 USC 105 and is also made available for use under a CCO license.

METABOLIC PROFILING AND COVID-19 DEATH

(PDeathLabs) for each subject. The ROC area for PDeathLabs was $0.785 \pm 0.002$. For comparison, single factor logistic models were developed for age at diagnosis, the 2-year Charleson Co-morbidity Index score (Charl2Yrs), lifetime Charleson score (CharlEver), the Elixhauser 2-year score (Elix2Yrs), and lifetime Elixhauser score (ElixEver). Their predicted probabilities were used to derive an ROC area for each. No difference was found in the ROC areas of PDeathLabs and age at diagnosis $(0.783 \pm 0.002 ; \mathrm{P}>0.05)$. However, the ROC area for PDeathLabs was significantly greater than that of Charl2Yrs $(0.704 \pm 0.002 ; \mathrm{P}<0.001)$, CharlEver $(0.729 \pm 0.002 ; \mathrm{P}<0.001)$, Elix2Yrs $(0.675 \pm 0.002 ; \mathrm{P}<0.001)$, and ElixEver $(0.707$ $\pm 0.002 ; P<0.001)$. Thus, baseline metabolic measurements outperform co-morbidity scores for pre-existing conditions in predicting COVID-19 deaths.

\section{DISCUSSION}

In this manuscript, we propose a novel method for handling pre-existing findings from vital signs and laboratory tests in models predicting COVID-19 death. Our observations confirm that they should be included because they have independent prognostic significance, generate insights into the mechanism of action, and may even be targets for interventions to mitigate the risk. By including explanatory variables, models can become hypothesis-generating and lead to future studies validating the suspected pathogenesis or trials of interventions targeting the abnormality itself.

All 13 parameters were identified as predictors of death in the subset models. These observations provide some justification to the approach that clinicians use to evaluate metabolic status. It is comforting to know that our parameters and the approach used in clinical practice converge upon a common set of criteria. Our main model showed that many parameters besides the most recent value were significant contributors to COVID-19 death. For 2 CM, disease burden contributed to the prediction while the most recent value did not. For 6 others, both current metabolic control and the long-term parameters were independently predictive of death. This finding suggests that $\mathrm{CM}$ have chronic and acute effects on the likelihood of 
medRxiv preprint doi: https://doi.org/10.1101/2022.01.22.22269691; this version posted February 22, 2022. The copyright holder for this preprint

(which was not certified by peer review) is the author/funder, who has granted medRxiv a license to display the preprint in perpetuity.

This article is a US Government work. It is not subject to copyright under 17 USC 105 and is also made available for use under a CCO license.

METABOLIC PROFILING AND COVID-19 DEATH

recovery from COVID-19 infection and that the former should routinely be considered for prediction models. Our results confirm the importance of CM parameters for COVID-19 prognosis, validate the attributes that they represent, and point out the hazards of using the most recent value as the most representative one.

This study illustrates the complex interactions that become apparent when multiple $\mathrm{CM}$ are studied in context. Higher values for O2Value1 and O2TimeWtAvg in our main model independently decreased the risk of death. This observation implies that the metabolic consequences of acute hypoxia and the burden imposed by chronic hypoxia create a substrate for COVID-19 injury. The latter may have done so through secondary pulmonary hypertension or may have simply been a marker for severe lung disease. Of 4 BP parameters, only SBPTimeWtAvg was a risk factor for COVID-19 death. Higher values for DBPValue1 and DBPTimeWtAvg were protective. This paradoxical effect might be explained by the fact that, for a given level of risk posed by SBP, a higher DBP is associated with a lower pulse pressure, reduced systolic wall stress, and better coronary perfusion. In a previous study, we showed that hypertension is the most important independent risk factor for COVID-19 death (6). This analysis suggests that the most important mechanism is long-term elevation of SBP. BMI and obesity are considered risk factors for COVID-related death $(2,5)$. However, we found that higher values for BMIValue1 in the main model lowered the risk of death. This discrepancy might be explained by the fact that we controlled for the mediators of injury in obesity (SBP, DBP, A1C, HDL, and LDL). Once these factors are considered, a higher BMI may only be a marker of better nutrition. This finding illustrates the hazards of drawing conclusions from incompletely specified models. Serum albumin and hematocrit are indicators of nutritional status or catabolism and are powerful predictors of recovery from acute illness. On the other hand, they do not produce cumulative organ injury over years. Accordingly, ALBValue1 and HCTValue1 were included in the main model but not their long-term parameters. A high value for A1CValue1 was identified as a risk factor while measures of disease burden were not. Thus, 
medRxiv preprint doi: https://doi.org/10.1101/2022.01.22.22269691; this version posted February 22, 2022. The copyright holder for this preprint

(which was not certified by peer review) is the author/funder, who has granted medRxiv a license to display the preprint in perpetuity.

This article is a US Government work. It is not subject to copyright under 17 USC 105 and is also made available for use under a CCO license.

METABOLIC PROFILING AND COVID-19 DEATH

recent hyperglycemia is deleterious in COVID-19 infection but microvascular injury developing over decades may not play that much of a role. Likewise, HDLValue1 had a protective effect while the long-term parameters did not. Finally, we found that time-weighted averages and abnormal AUC were both included as measures of disease burden for EGFR, ALT, LDL, and O2SAT. For the last 3, the effects were in opposite directions. These results imply that abnormal AUC provides information about risk beyond the time weighted average. This study shows that there is no justification for selecting one arbitrary parameter of a CM for modeling over the others unless there is a physiologic basis for doing so.

We also found that temporal instability in a $\mathrm{CM}$ - whether reflected in long- or short-term trends, coefficient of variation, or tendency to relapse - had significant effects on prognosis. The direction and magnitude of this effect varied from $\mathrm{CM}$ to $\mathrm{CM}$ and, at times, were unexpected. Future studies should be done to identify the mechanisms by which fluctuations in CM affect recovery from COVID-19 infection. Until then, it is reasonable to include temporal changes of CM in models of COVID-19 death. This recommendation is consistent with the way that clinicians prioritize treatment of abnormal values. For example, many would consider a patient whose A1c rapidly increased from 5.0 to 8.5 to have a poorer prognosis than one whose A1c decreased from 11.0 to 9.0 .

As expected, measures of chronicity added little to the model once disease burden was considered. The minimal contribution from refractoriness suggests that clustering adds very little to the prognosis compared to the same abnormalities scattered over the patient's timeline. Nevertheless, it remains a useful clinical concept because it identifies patients for whom further treatment may be futile.

We calculated a predicted probability of death (PDeathLabs) based upon complete value sets for $11 \mathrm{CM}$. The ROC area indicated that vital signs and laboratory findings are powerful predictors of outcomes. In fact, the ROC areas for PDeathLabs and age at diagnosis were equivalent, while PDeathLabs was consistently superior to Charl2Yrs, CharlEver, Elix2Yrs, and 
medRxiv preprint doi: https://doi.org/10.1101/2022.01.22.22269691; this version posted February 22, 2022. The copyright holder for this preprint

(which was not certified by peer review) is the author/funder, who has granted medRxiv a license to display the preprint in perpetuity.

This article is a US Government work. It is not subject to copyright under 17 USC 105 and is also made available for use under a CCO license.

METABOLIC PROFILING AND COVID-19 DEATH

ElixEver. In summary, this term was a very convenient way to summarize millions of observations for CM done on hundreds of thousands of patients. Its greatest utility would be as a covariate in a parent model containing many other domains.

We did not include age in our model for PDeathLabs for several reasons. First, it was intended to represent pre-existing clinical measurements in an overarching model containing multiple domains. One domain was comprised of demographic characteristics including age at diagnosis. Next, we did not want age to displace clinical parameters in the model highly correlated with age such as blood pressure or weight. To understand the mechanisms that lead to a fatal outcome, explanatory variables should take precedence over disease markers. They may even be targets for an intervention. Finally, models based upon demographics do not support decision-making at the point of care. For example, a physician might feel comfortable withdrawing care if the patient had refractory hypoxemia or terminal renal failure - but not simply because the patient was old. Clinicians make recommendations based upon an assessment of the underlying conditions. It is the patient's prerogative to decide what is appropriate based upon age and quality of life.

Of course, our conclusions are limited to patients with characteristics like the veteran population. Moreover, this study was confined to patients with chronic illnesses that required long-term follow-up and periodic health screening. It is unclear if our conclusions are applicable to patients without such indications. Further studies should be done on other populations and disease states before the method should be widely applied. If validated by others, our method could revolutionize the way in which clinic measurements are handled in multivariate models. 
medRxiv preprint doi: https://doi.org/10.1101/2022.01.22.22269691; this version posted February 22, 2022. The copyright holder for this preprint (which was not certified by peer review) is the author/funder, who has granted medRxiv a license to display the preprint in perpetuity. This article is a US Government work. It is not subject to copyright under 17 USC 105 and is also made available for use under a CCO license.

METABOLIC PROFILING AND COVID-19 DEATH

TABLE 1: MULTIVARIATE MODEL FOR COVID-19 DEATH BASED ON BASELINE METABOLIC PROFILES

\begin{tabular}{|c|c|c|c|c|c|c|}
\hline Parameter & Coefficient & Std Error & Z_Score & P_Value & Lower $\mathrm{Cl}$ & Higher $\mathrm{Cl}$ \\
\hline O2Value1 & -0.0731 & 0.0071 & 10.3300 & 0.0000 & -0.0869 & -0.0592 \\
\hline SBPValue1 & -0.0040 & 0.0009 & -4.5700 & 0.0000 & -0.0058 & -0.0023 \\
\hline DBPValue1 & -0.0082 & 0.0018 & -4.6700 & 0.0000 & -0.0117 & -0.0048 \\
\hline BMIValue1 & -0.0254 & 0.0017 & -15.1600 & 0.0000 & -0.0287 & -0.0221 \\
\hline ALTValue1 & -0.0036 & 0.0010 & -3.4400 & 0.0010 & -0.0056 & -0.0015 \\
\hline AlbValue1 & -0.5831 & 0.0289 & -20.2000 & 0.0000 & -0.6396 & -0.5265 \\
\hline HctValue1 & -0.0115 & 0.0027 & -4.2200 & 0.0000 & -0.0169 & -0.0062 \\
\hline A1cValue1 & 0.0324 & 0.0067 & 4.8200 & 0.0000 & 0.0192 & 0.0456 \\
\hline HDLValue1 & -0.0031 & 0.0008 & -3.8300 & 0.0000 & -0.0047 & -0.0015 \\
\hline O2TimeWtAvg & -0.1485 & 0.0092 & -16.2000 & 0.0000 & -0.1664 & -0.1305 \\
\hline SBPTimeWtAvg & 0.0297 & 0.0013 & 22.2300 & 0.0000 & 0.0271 & 0.0323 \\
\hline DBPTimeWtAvg & -0.0424 & 0.0021 & -19.9300 & 0.0000 & -0.0466 & -0.0383 \\
\hline EGFRTimeWtAvg & -0.0131 & 0.0009 & -15.3100 & 0.0000 & -0.0148 & -0.0115 \\
\hline ALTTimeWtAvg & -0.0186 & 0.0021 & -8.8000 & 0.0000 & -0.0228 & -0.0145 \\
\hline LDLTimeWtAvg & -0.0074 & 0.0006 & -11.7900 & 0.0000 & -0.0086 & -0.0062 \\
\hline O2AbnAUC & -0.0001 & 0.0000 & -7.6200 & 0.0000 & -0.0001 & -0.0001 \\
\hline EGFRAbnAUC & 0.0000 & 0.0000 & 3.9700 & 0.0000 & 0.0000 & 0.0000 \\
\hline LDLAbnAUC & 0.0000 & 0.0000 & 5.3500 & 0.0000 & 0.0000 & 0.0000 \\
\hline ALTAbnAUC & 0.0000 & 0.0000 & 7.5600 & 0.0000 & 0.0000 & 0.0000 \\
\hline SBPNumAboveGoal & -0.0010 & 0.0002 & -5.5200 & 0.0000 & -0.0014 & -0.0006 \\
\hline BMINumAboveGoal & -0.0018 & 0.0004 & -4.9200 & 0.0000 & -0.0025 & -0.0011 \\
\hline LDLNumAboveGoal & 0.0075 & 0.0021 & 3.5500 & 0.0000 & 0.0033 & 0.0116 \\
\hline HDLFUDaysBelowGoal & 0.0000 & 0.0000 & 3.5300 & 0.0000 & 0.0000 & 0.0000 \\
\hline AlbCtBelowGoal & -0.0128 & 0.0043 & -2.9400 & 0.0030 & -0.0213 & -0.0043 \\
\hline LDLTimeAboveGoal & 0.0000 & 0.0000 & -1.9900 & 0.0460 & 0.0000 & 0.0000 \\
\hline HDLTimeBelowGoal & 0.0000 & 0.0000 & -3.3100 & 0.0010 & 0.0000 & 0.0000 \\
\hline EGFRMeanValDiff & 0.0126 & 0.0026 & 4.8700 & 0.0000 & 0.0075 & 0.0176 \\
\hline AlbMeanValDiff & -0.4072 & 0.1128 & -3.6100 & 0.0000 & -0.6282 & -0.1862 \\
\hline SBPCoeffVar & 0.0643 & 0.0036 & 17.6700 & 0.0000 & 0.0572 & 0.0715 \\
\hline BMICoeffVar & 0.0152 & 0.0024 & 6.2600 & 0.0000 & 0.0104 & 0.0199 \\
\hline AlbCoeffVar & 0.0136 & 0.0030 & 4.5500 & 0.0000 & 0.0077 & 0.0194 \\
\hline HctCoeffVar & 0.0137 & 0.0023 & 6.0500 & 0.0000 & 0.0092 & 0.0181 \\
\hline SBPNumClust & 0.0021 & 0.0004 & 5.0300 & 0.0000 & 0.0013 & 0.0029 \\
\hline EGFRNumClust & 0.0112 & 0.0033 & 3.3700 & 0.0010 & 0.0047 & 0.0177 \\
\hline ALTNumClust & 0.0254 & 0.0059 & 4.3500 & 0.0000 & 0.0140 & 0.0369 \\
\hline AlbNumClust & -0.0227 & 0.0074 & -3.0800 & 0.0020 & -0.0372 & -0.0082 \\
\hline HctNumClust & -0.0150 & 0.0040 & -3.7800 & 0.0000 & -0.0228 & -0.0072 \\
\hline LDLNumClust & 0.0304 & 0.0064 & 4.7700 & 0.0000 & 0.0179 & 0.0429 \\
\hline A1cNumClust & 0.0423 & 0.0067 & 6.3300 & 0.0000 & 0.0292 & 0.0554 \\
\hline O2Lag3Dev & 3.8382 & 0.4806 & 7.9900 & 0.0000 & 2.8962 & 4.7803 \\
\hline SBPLag3Dev & 0.3222 & 0.1195 & 2.7000 & 0.0070 & 0.0879 & 0.5565 \\
\hline DBPLag3Dev & 0.3167 & 0.1249 & 2.5300 & 0.0110 & 0.0718 & 0.5616 \\
\hline
\end{tabular}


medRxiv preprint doi: https://doi.org/10.1101/2022.01.22.22269691; this version posted February 22, 2022. The copyright holder for this preprint (which was not certified by peer review) is the author/funder, who has granted medRxiv a license to display the preprint in perpetuity. This article is a US Government work. It is not subject to copyright under 17 USC 105 and is also made available for use under a CCO license.

METABOLIC PROFILING AND COVID-19 DEATH

\begin{tabular}{|l|r|r|r|r|r|r|}
\hline EGFRLag3Dev & -0.1797 & 0.0531 & -3.3800 & 0.0010 & -0.2839 & -0.0756 \\
\hline LDLLag3Dev & 0.1140 & 0.0317 & 3.6000 & 0.0000 & 0.0519 & 0.1761 \\
\hline O2NetChange & 0.0098 & 0.0039 & 2.5100 & 0.0120 & 0.0022 & 0.0175 \\
\hline AlbNetChange & 0.1491 & 0.0234 & 6.3800 & 0.0000 & 0.1032 & 0.1949 \\
\hline HctNetChange & -0.0161 & 0.0025 & -6.4100 & 0.0000 & -0.0210 & -0.0112 \\
\hline LDLNetChange & -0.0006 & 0.0002 & -2.3700 & 0.0180 & -0.0011 & -0.0001 \\
\hline A1cNetChange & 0.0260 & 0.0063 & 4.1000 & 0.0000 & 0.0136 & 0.0384 \\
\hline Constant & 23.4159 & 0.7186 & 32.5800 & 0.0000 & 22.0075 & 24.8244 \\
\hline
\end{tabular}


medRxiv preprint doi: https://doi.org/10.1101/2022.01.22.22269691; this version posted February 22, 2022. The copyright holder for this preprint (which was not certified by peer review) is the author/funder, who has granted medRxiv a license to display the preprint in perpetuity. This article is a US Government work. It is not subject to copyright under 17 USC 105 and is also made available for use under a CCO license.

METABOLIC PROFILING AND COVID-19 DEATH

\section{APPENDIX A: MULTIVARIATE MODEL FOR COVID-19 DEATH USING O2 PARAMETERS}

\begin{tabular}{|l|r|r|r|r|r|r|}
\hline Parameter & \multicolumn{1}{|c|}{ Coefficient } & \multicolumn{1}{l|}{ Std Error } & \multicolumn{1}{l|}{ Z_Score } & \multicolumn{1}{l|}{ P_Value } & \multicolumn{1}{l|}{ Lower Cl } & \multicolumn{1}{l|}{ Higher Cl } \\
\hline O2Value1 & -0.0556 & 0.0068 & -8.2000 & 0.0000 & -0.0689 & -0.0423 \\
\hline O2AbnAUC & -0.0002 & 0.0000 & -14.3000 & 0.0000 & -0.0002 & -0.0002 \\
\hline O2NetChange & 0.0098 & 0.0033 & 3.0000 & 0.0030 & 0.0034 & 0.0162 \\
\hline O2TimeWtAvg & -0.2119 & 0.0082 & -25.7100 & 0.0000 & -0.2281 & -0.1958 \\
\hline O2NumBelowGoal & -0.0619 & 0.0089 & -6.9800 & 0.0000 & -0.0793 & -0.0445 \\
\hline O2FUDaysBelowGoal & 0.0019 & 0.0008 & 2.4200 & 0.0150 & 0.0004 & 0.0034 \\
\hline O2TimeBelowGoal & 0.0015 & 0.0013 & 1.1700 & 0.2420 & -0.0010 & 0.0041 \\
\hline O2CtBelowGoal & -0.1598 & 0.0918 & -1.7400 & 0.0820 & -0.3398 & 0.0201 \\
\hline O2NumClust & 0.1202 & 0.0119 & 10.1000 & 0.0000 & 0.0968 & 0.1435 \\
\hline O2MaxClustDays & -0.0001 & 0.0010 & -0.0600 & 0.9540 & -0.0019 & 0.0018 \\
\hline O2Lag3Dev & 3.1339 & 0.4382 & 7.1500 & 0.0000 & 2.2749 & 3.9928 \\
\hline O2MeanValDiff & -0.2083 & 0.0151 & -13.8300 & 0.0000 & -0.2378 & -0.1788 \\
\hline O2CoeffVar & 0.2091 & 0.0112 & 18.6400 & 0.0000 & 0.1871 & 0.2311 \\
\hline Constant & 23.0275 & 0.5770 & 39.9100 & 0.0000 & 21.8966 & 24.1584 \\
\hline
\end{tabular}

$n=299,311 ; R O C=0.643$

APPENDIX B: MULTIVARIATE MODEL FOR COVID-19 DEATH USING SBP PARAMETERS

\begin{tabular}{|l|r|r|r|r|r|r|}
\hline \multicolumn{1}{|c|}{ Parameter } & \multicolumn{1}{c|}{ Coefficient } & \multicolumn{1}{c|}{ Std Error } & \multicolumn{1}{c|}{ Z_Score } & \multicolumn{1}{c|}{ P_Value } & \multicolumn{1}{c|}{ Lower Cl } & \multicolumn{1}{c|}{ Higher Cl } \\
\hline SBPValue1 & -0.0039 & 0.0009 & -4.5500 & 0.0000 & -0.0056 & -0.0022 \\
\hline SBPAbnAUC & 0.0000 & 0.0000 & -7.1200 & 0.0000 & 0.0000 & 0.0000 \\
\hline SBPNetChange & -0.0060 & 0.0004 & -13.9000 & 0.0000 & -0.0069 & -0.0052 \\
\hline SBPTimeWtAvg & 0.0092 & 0.0013 & 7.0300 & 0.0000 & 0.0066 & 0.0118 \\
\hline SBPNumAboveGoal & -0.0011 & 0.0002 & -7.3200 & 0.0000 & -0.0014 & -0.0008 \\
\hline SBPFUDaysAboveGoal & 0.0004 & 0.0000 & 18.7000 & 0.0000 & 0.0004 & 0.0005 \\
\hline SBPTimeAboveGoal & -0.0002 & 0.0001 & -2.6100 & 0.0090 & -0.0003 & 0.0000 \\
\hline SBPCtAboveGoal & 0.0100 & 0.0035 & 2.8200 & 0.0050 & 0.0030 & 0.0169 \\
\hline SBPNumClust & 0.0039 & 0.0004 & 10.6800 & 0.0000 & 0.0032 & 0.0046 \\
\hline SBPMaxClustDays & -0.0003 & 0.0000 & -12.4200 & 0.0000 & -0.0004 & -0.0003 \\
\hline SBPLag3Dev & 0.6649 & 0.0879 & 7.5600 & 0.0000 & 0.4925 & 0.8372 \\
\hline SBPMeanValDiff & -0.0152 & 0.0028 & -5.5300 & 0.0000 & -0.0207 & -0.0098 \\
\hline SBPCoeffVar & 0.1830 & 0.0035 & 51.5700 & 0.0000 & 0.1760 & 0.1899 \\
\hline Constant & -5.4780 & 0.1413 & -38.7600 & 0.0000 & -5.7550 & -5.2010 \\
\hline
\end{tabular}

$\mathrm{n}=\mathbf{3 1 0}, \mathbf{8 0 0} ; \mathrm{R}=\mathbf{0 . 7 1 1}$

APPENDIX C: MULTIVARIATE MODEL FOR COVID-19 DEATH USING DBP PARAMETERS

\begin{tabular}{|l|r|r|r|r|r|r|}
\hline Parameter & \multicolumn{1}{|c|}{ Coefficient } & \multicolumn{1}{l|}{ Std Error } & \multicolumn{1}{l|}{ Z_Score } & \multicolumn{1}{l|}{ P_Value } & \multicolumn{1}{l|}{ LowCl } & \multicolumn{1}{l|}{ HighCl } \\
\hline DBPValue1 & -0.0243 & 0.0015 & -15.8600 & 0.0000 & -0.0273 & -0.0213 \\
\hline DBPAbnAUC & 0.0000 & 0.0000 & 3.4200 & 0.0010 & 0.0000 & 0.0000 \\
\hline DBPNetChange & -0.0137 & 0.0007 & -19.1300 & 0.0000 & -0.0151 & -0.0123 \\
\hline DBPTimeWtAvg & -0.0329 & 0.0019 & -17.5200 & 0.0000 & -0.0366 & -0.0292 \\
\hline DBPNumAboveGoal & -0.0042 & 0.0007 & -6.4600 & 0.0000 & -0.0055 & -0.0029 \\
\hline DBPFUDaysAboveGoal & 0.0002 & 0.0001 & 3.7800 & 0.0000 & 0.0001 & 0.0004 \\
\hline DBPTimeAboveGoal & -0.0002 & 0.0002 & -0.8800 & 0.3760 & -0.0005 & 0.0002 \\
\hline
\end{tabular}


medRxiv preprint doi: https://doi.org/10.1101/2022.01.22.22269691; this version posted February 22, 2022. The copyright holder for this preprint (which was not certified by peer review) is the author/funder, who has granted medRxiv a license to display the preprint in perpetuity. This article is a US Government work. It is not subject to copyright under 17 USC 105 and is also made available for use under a CCO license.

METABOLIC PROFILING AND COVID-19 DEATH

\begin{tabular}{|l|r|r|r|r|r|r|}
\hline DBPCtAboveGoal & 0.0501 & 0.0133 & 3.7700 & 0.0000 & 0.0240 & 0.0761 \\
\hline DBPNumClust & 0.0101 & 0.0011 & 9.3300 & 0.0000 & 0.0080 & 0.0122 \\
\hline DBPMaxClustDays & -0.0002 & 0.0001 & -3.3300 & 0.0010 & -0.0004 & -0.0001 \\
\hline DBPLag3Dev & 1.5364 & 0.0878 & 17.4900 & 0.0000 & 1.3642 & 1.7085 \\
\hline DBPMeanValDiff & -0.1277 & 0.0052 & -24.5500 & 0.0000 & -0.1379 & -0.1175 \\
\hline DBPCoeffVar & 0.1646 & 0.0037 & 44.8700 & 0.0000 & 0.1574 & 0.1718 \\
\hline Constant & 0.5617 & 0.1176 & 4.7800 & 0.0000 & 0.3312 & 0.7922 \\
\hline
\end{tabular}

$\mathrm{n}=310,792 ; \mathrm{ROC}=0.705$

APPENDIX D: MULTIVARIATE MODEL FOR COVID-19 DEATH USING BMI PARAMETERS

\begin{tabular}{|l|r|r|r|r|r|r|}
\hline Parameter & \multicolumn{1}{|c|}{ Coefficient } & \multicolumn{1}{l|}{ Std Error } & \multicolumn{1}{l|}{ Z_Score } & \multicolumn{1}{l|}{ P_Value } & \multicolumn{1}{l|}{ Lower Cl } & \multicolumn{1}{l|}{ Higher Cl } \\
\hline BMIValue1 & -0.0547 & 0.0053 & -10.3200 & 0.0000 & -0.0650 & -0.0443 \\
\hline BMIAbnAUC & 0.0000 & 0.0000 & 13.3800 & 0.0000 & 0.0000 & 0.0000 \\
\hline BMINetChange & -0.0338 & 0.0028 & -11.8800 & 0.0000 & -0.0394 & -0.0282 \\
\hline BMITimeWtAvg & -0.0017 & 0.0058 & -0.3000 & 0.7630 & -0.0131 & 0.0096 \\
\hline BMINumAboveGoal & -0.0025 & 0.0006 & -4.0600 & 0.0000 & -0.0037 & -0.0013 \\
\hline BMIFUDaysAboveGoal & 0.0001 & 0.0000 & 6.8900 & 0.0000 & 0.0001 & 0.0002 \\
\hline BMITimeAboveGoal & -0.0001 & 0.0000 & -5.9800 & 0.0000 & -0.0001 & 0.0000 \\
\hline BMICtAboveGoal & 0.0053 & 0.0008 & 7.0300 & 0.0000 & 0.0038 & 0.0068 \\
\hline BMINumClust & 0.0493 & 0.0050 & 9.8100 & 0.0000 & 0.0395 & 0.0592 \\
\hline BMIMaxClustDays & 0.0000 & 0.0000 & -0.8400 & 0.4010 & -0.0001 & 0.0000 \\
\hline BMILag3Dev & -0.1520 & 0.1522 & -1.0000 & 0.3180 & -0.4503 & 0.1462 \\
\hline BMIMeanValDiff & -0.2505 & 0.0165 & -15.1800 & 0.0000 & -0.2828 & -0.2181 \\
\hline BMICoeffVar & 0.0596 & 0.0027 & 21.7500 & 0.0000 & 0.0542 & 0.0650 \\
\hline Constant & -1.4756 & 0.0728 & -20.2600 & 0.0000 & -1.6184 & -1.3329 \\
\hline
\end{tabular}

$n=296,942 ;$ ROC $=0.650$

APPENDIX E: MULTIVARIATE MODEL FOR COVID-19 DEATH USING EGFR PARAMETERS

\begin{tabular}{|l|r|r|r|r|r|r|}
\hline \multicolumn{1}{|c|}{ Parameter } & Coefficient & \multicolumn{1}{c|}{ Std Error } & \multicolumn{1}{c|}{ Z_Score } & \multicolumn{1}{c|}{ P_Value } & \multicolumn{1}{c|}{ Lower Cl } & \multicolumn{1}{c|}{ Higher Cl } \\
\hline EGFRValue1 & -0.0091 & 0.0011 & -8.3600 & 0.0000 & -0.0113 & -0.0070 \\
\hline EGFRAbnAUC & 0.0000 & 0.0000 & 5.5800 & 0.0000 & 0.0000 & 0.0000 \\
\hline EGFRNetChange & 0.0064 & 0.0006 & 10.3000 & 0.0000 & 0.0051 & 0.0076 \\
\hline EGFRTimeWtAvg & -0.0096 & 0.0012 & -8.0400 & 0.0000 & -0.0119 & -0.0072 \\
\hline EGFRNumBelowGoal & -0.0054 & 0.0009 & -5.9700 & 0.0000 & -0.0072 & -0.0036 \\
\hline EGFRFUDaysBelowGoal & 0.0002 & 0.0000 & 5.7200 & 0.0000 & 0.0001 & 0.0002 \\
\hline EGFRTimeBelowGoal & -0.0001 & 0.0000 & -3.2600 & 0.0010 & -0.0001 & 0.0000 \\
\hline EGFRCtBelowGoal & 0.0070 & 0.0010 & 6.9500 & 0.0000 & 0.0050 & 0.0090 \\
\hline EGFRNumClust & 0.0879 & 0.0037 & 23.7900 & 0.0000 & 0.0807 & 0.0952 \\
\hline EGFRMaxClustDays & 0.0000 & 0.0000 & -0.3800 & 0.7070 & -0.0001 & 0.0001 \\
\hline EGFRLag3Dev & -0.0054 & 0.0568 & -0.0900 & 0.9250 & -0.1166 & 0.1059 \\
\hline EGFRMeanValDiff & 0.0058 & 0.0020 & 2.9300 & 0.0030 & 0.0019 & 0.0097 \\
\hline EGFRCoeffVar & 0.0198 & 0.0010 & 18.8900 & 0.0000 & 0.0178 & 0.0219 \\
\hline Constant & -2.0081 & 0.0567 & -35.4100 & 0.0000 & -2.1192 & -1.8970 \\
\hline
\end{tabular}

$n=294,314 ;$ ROC $=0.691$ 
medRxiv preprint doi: https://doi.org/10.1101/2022.01.22.22269691; this version posted February 22, 2022. The copyright holder for this preprint (which was not certified by peer review) is the author/funder, who has granted medRxiv a license to display the preprint in perpetuity. This article is a US Government work. It is not subject to copyright under 17 USC 105 and is also made available for use under a CCO license.

METABOLIC PROFILING AND COVID-19 DEATH

\section{APPENDIX F: MULTIVARIATE MODEL FOR COVID-19 DEATH USING ALB PARAMETERS}

\begin{tabular}{|l|r|r|r|r|r|r|}
\hline \multicolumn{1}{|c|}{ Parameter } & \multicolumn{1}{c|}{ Coefficient } & \multicolumn{1}{c|}{ Std Error } & \multicolumn{1}{c|}{ Z_Score } & \multicolumn{1}{c|}{ P_Value } & \multicolumn{1}{c|}{ Lower Cl } & \multicolumn{1}{c|}{ HigherCl } \\
\hline AlbValue1 & -1.2062 & 0.0428 & -28.1500 & 0.0000 & -1.2902 & -1.1223 \\
\hline AlbAbnAUC & -0.0015 & 0.0002 & -6.7600 & 0.0000 & -0.0019 & -0.0010 \\
\hline AlbNetChange & 0.1897 & 0.0252 & 7.5200 & 0.0000 & 0.1403 & 0.2392 \\
\hline AlbTimeWtAvg & -0.1302 & 0.0458 & -2.8500 & 0.0040 & -0.2199 & -0.0405 \\
\hline AlbNumBelowGoal & -0.0179 & 0.0024 & -7.4900 & 0.0000 & -0.0226 & -0.0132 \\
\hline AlbFUDaysBelowGoal & 0.0007 & 0.0002 & 3.0100 & 0.0030 & 0.0002 & 0.0012 \\
\hline AlbTimeBelowGoal & 0.0002 & 0.0002 & 1.3500 & 0.1760 & -0.0001 & 0.0005 \\
\hline AlbCtBelowGoal & -0.0408 & 0.0060 & -6.8500 & 0.0000 & -0.0525 & -0.0291 \\
\hline AlbNumClust & 0.0737 & 0.0086 & 8.6000 & 0.0000 & 0.0569 & 0.0905 \\
\hline AlbMaxClustDays & -0.0002 & 0.0003 & -0.8900 & 0.3730 & -0.0008 & 0.0003 \\
\hline AlbLag3Dev & 0.8988 & 0.1077 & 8.3400 & 0.0000 & 0.6877 & 1.1100 \\
\hline AlbMeanValDiff & -1.3064 & 0.0959 & -13.6300 & 0.0000 & -1.4943 & -1.1185 \\
\hline AlbCoeffVar & 0.0633 & 0.0029 & 22.1700 & 0.0000 & 0.0577 & 0.0689 \\
\hline Constant & 2.3914 & 0.1173 & 20.3800 & 0.0000 & 2.1615 & 2.6214 \\
\hline
\end{tabular}

$\mathrm{n}=286,066 ; \mathrm{ROC}=0.693$

APPENDIX G: MULTIVARIATE MODEL FOR COVID-19 DEATH USING HCT VALUES

\begin{tabular}{|l|r|r|r|r|r|r|}
\hline \multicolumn{1}{|c|}{ Parameter } & \multicolumn{1}{c|}{ Coefficient } & \multicolumn{1}{c|}{ Std Error } & \multicolumn{1}{c|}{ Z_Score } & \multicolumn{1}{c|}{ P_Value } & \multicolumn{1}{c|}{ Lower Cl } & \multicolumn{1}{c|}{ Higher Cl } \\
\hline HctValue1 & -0.0312 & 0.0042 & -7.4900 & 0.0000 & -0.0393 & -0.0230 \\
\hline HctAbnAUC & -0.0001 & 0.0000 & -3.8300 & 0.0000 & -0.0001 & 0.0000 \\
\hline HctNetChange & -0.0437 & 0.0029 & -15.1900 & 0.0000 & -0.0493 & -0.0380 \\
\hline HctTimeWtAvg & -0.0249 & 0.0045 & -5.5500 & 0.0000 & -0.0337 & -0.0161 \\
\hline HctNumBelowGoal & -0.0065 & 0.0009 & -6.9500 & 0.0000 & -0.0083 & -0.0046 \\
\hline HctFUDaysBelowGoal & 0.0005 & 0.0001 & 4.4100 & 0.0000 & 0.0003 & 0.0008 \\
\hline HctTimeBelowGoal & 0.0002 & 0.0001 & 2.2000 & 0.0280 & 0.0000 & 0.0005 \\
\hline HctCtBelowGoal & -0.0100 & 0.0025 & -3.9200 & 0.0000 & -0.0149 & -0.0050 \\
\hline HctNumClust & 0.0406 & 0.0049 & 8.2600 & 0.0000 & 0.0310 & 0.0503 \\
\hline HctMaxClustDays & -0.0004 & 0.0002 & -2.8100 & 0.0050 & -0.0007 & -0.0001 \\
\hline HctLag3Dev & 0.4425 & 0.1106 & 4.0000 & 0.0000 & 0.2258 & 0.6592 \\
\hline HctMeanValDiff & -0.0812 & 0.0107 & -7.5600 & 0.0000 & -0.1023 & -0.0602 \\
\hline HctCoeffVar & 0.0764 & 0.0023 & 32.9700 & 0.0000 & 0.0718 & 0.0809 \\
\hline Constant & -0.9129 & 0.1121 & -8.1400 & 0.0000 & -1.1327 & -0.6931 \\
\hline
\end{tabular}

$\mathrm{n}=296,165 ; \mathrm{ROC}=0.687$

APPENDIX H: MULTIVARIATE MODEL FOR COVID-19 DEATH USING LDL PARAMETERS

\begin{tabular}{|l|r|r|r|r|r|r|}
\hline \multicolumn{1}{|c|}{ Parameter } & \multicolumn{1}{c|}{ Coefficient } & \multicolumn{1}{c|}{ Std Error } & \multicolumn{1}{c|}{ Z_Score } & \multicolumn{1}{c|}{ P_Value } & \multicolumn{1}{c|}{ Lower Cl } & \multicolumn{1}{c|}{ Higher Cl } \\
\hline LDLValue1 & 0.0002 & 0.0006 & 0.2500 & 0.8020 & -0.0011 & 0.0014 \\
\hline LDLAbnAUC & 0.0000 & 0.0000 & 15.0800 & 0.0000 & 0.0000 & 0.0000 \\
\hline LDLNetChange & -0.0019 & 0.0003 & -6.3900 & 0.0000 & -0.0025 & -0.0013 \\
\hline LDLTimeWtAvg & -0.0185 & 0.0008 & -21.8600 & 0.0000 & -0.0201 & -0.0168 \\
\hline LDLNumAboveGoal & 0.0132 & 0.0028 & 4.7600 & 0.0000 & 0.0078 & 0.0186 \\
\hline LDLFUDaysAboveGoal & -0.0001 & 0.0000 & -2.4600 & 0.0140 & -0.0001 & 0.0000 \\
\hline LDLTimeAboveGoal & -0.0001 & 0.0000 & -6.0800 & 0.0000 & -0.0001 & -0.0001 \\
\hline
\end{tabular}


medRxiv preprint doi: https://doi.org/10.1101/2022.01.22.22269691; this version posted February 22, 2022. The copyright holder for this preprint (which was not certified by peer review) is the author/funder, who has granted medRxiv a license to display the preprint in perpetuity. This article is a US Government work. It is not subject to copyright under 17 USC 105 and is also made available for use under a CCO license.

METABOLIC PROFILING AND COVID-19 DEATH

\begin{tabular}{|l|r|r|r|r|r|r|}
\hline LDLCtAboveGoal & 0.0194 & 0.0052 & 3.7600 & 0.0000 & 0.0093 & 0.0295 \\
\hline LDLNumClust & 0.1059 & 0.0064 & 16.4900 & 0.0000 & 0.0933 & 0.1185 \\
\hline LDLMaxClustDays & 0.0000 & 0.0000 & 1.7300 & 0.0840 & 0.0000 & 0.0001 \\
\hline LDLLag3Dev & -0.0997 & 0.0400 & -2.4900 & 0.0130 & -0.1780 & -0.0213 \\
\hline LDLMeanValDiff & -0.0149 & 0.0013 & -11.2500 & 0.0000 & -0.0175 & -0.0123 \\
\hline LDLCoeffVar & 0.0203 & 0.0012 & 17.0700 & 0.0000 & 0.0180 & 0.0227 \\
\hline Constant & -1.5886 & 0.0610 & -26.0500 & 0.0000 & -1.7081 & -1.4691 \\
\hline
\end{tabular}

$\mathrm{n}=\mathbf{2 8 5}, \mathbf{4 2 3} ; \mathrm{ROC}=\mathbf{0 . 6 7 5}$

APPENDIX I: MULTIVARIATE MODEL FOR COVID-19 DEATH USING A1C PARAMETERS

\begin{tabular}{|l|r|r|r|r|r|r|}
\hline \multicolumn{1}{|c|}{ Parameter } & \multicolumn{1}{c|}{ Coefficient } & \multicolumn{1}{c|}{ Std Error } & \multicolumn{1}{c|}{ Z_Score } & \multicolumn{1}{c|}{ P_Value } & \multicolumn{1}{c|}{ Lower Cl } & \multicolumn{1}{c|}{ Higher Cl } \\
\hline A1cValue1 & -0.0044 & 0.0160 & -0.2800 & 0.7810 & -0.0357 & 0.0269 \\
\hline A1cAbnAUC & 0.0000 & 0.0000 & -5.1200 & 0.0000 & 0.0000 & 0.0000 \\
\hline A1cNetChange & -0.0168 & 0.0071 & -2.3600 & 0.0180 & -0.0307 & -0.0029 \\
\hline A1cTimeWtAvg & 0.0574 & 0.0213 & 2.7000 & 0.0070 & 0.0157 & 0.0991 \\
\hline A1cNumAboveGoal & 0.0016 & 0.0028 & 0.5800 & 0.5600 & -0.0039 & 0.0072 \\
\hline A1cFUDaysAboveGoal & 0.0001 & 0.0000 & 2.4100 & 0.0160 & 0.0000 & 0.0001 \\
\hline A1cTimeAboveGoal & -0.0001 & 0.0000 & -5.0200 & 0.0000 & -0.0001 & -0.0001 \\
\hline A1cCtAboveGoal & 0.0038 & 0.0032 & 1.1600 & 0.2450 & -0.0026 & 0.0101 \\
\hline A1cNumClust & 0.1518 & 0.0083 & 18.2900 & 0.0000 & 0.1355 & 0.1680 \\
\hline A1cMaxClustDays & 0.0002 & 0.0000 & 7.1300 & 0.0000 & 0.0001 & 0.0002 \\
\hline A1cLag3Dev & -0.1333 & 0.1004 & -1.3300 & 0.1840 & -0.3300 & 0.0634 \\
\hline A1cMeanValDiff & -0.2625 & 0.0399 & -6.5800 & 0.0000 & -0.3406 & -0.1843 \\
\hline A1cCoeffVar & 0.0223 & 0.0024 & 9.1000 & 0.0000 & 0.0175 & 0.0270 \\
\hline Constant & -3.5018 & 0.0793 & -44.1600 & 0.0000 & -3.6573 & -3.3464 \\
\hline
\end{tabular}

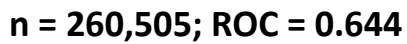

APPENDIX J: MULTIVARIATE MODEL FOR COVID-19 DEATH USING HDL PARAMETERS

\begin{tabular}{|l|r|r|r|r|r|r|}
\hline \multicolumn{1}{|c|}{ Parameter } & Coefficient & Std Error & Z_Score & P_Value & Lower Cl & Higher Cl \\
\hline HDLValue1 & -0.0005 & 0.0020 & -0.2600 & 0.7910 & -0.0046 & 0.0035 \\
\hline HDLAbnAUC & 0.0000 & 0.0000 & 1.7800 & 0.0760 & 0.0000 & 0.0000 \\
\hline HDLNetChange & -0.0012 & 0.0010 & -1.2200 & 0.2210 & -0.0032 & 0.0007 \\
\hline HDLTimeWtAvg & 0.0153 & 0.0023 & 6.7000 & 0.0000 & 0.0108 & 0.0198 \\
\hline HDLNumBelowGoal & 0.0189 & 0.0026 & 7.1600 & 0.0000 & 0.0137 & 0.0241 \\
\hline HDLFUDaysBelowGoal & 0.0000 & 0.0000 & -0.8600 & 0.3880 & -0.0001 & 0.0000 \\
\hline HDLTimeBelowGoal & 0.0000 & 0.0000 & -1.5900 & 0.1120 & -0.0001 & 0.0000 \\
\hline HDLCtBelowGoal & 0.0015 & 0.0037 & 0.4200 & 0.6750 & -0.0057 & 0.0088 \\
\hline HDLNumClust & 0.0966 & 0.0062 & 15.5000 & 0.0000 & 0.0844 & 0.1088 \\
\hline HDLMaxClustDays & 0.0001 & 0.0000 & 3.5600 & 0.0000 & 0.0000 & 0.0001 \\
\hline HDLLag3Dev & -0.2636 & 0.0731 & -3.6100 & 0.0000 & -0.4068 & -0.1203 \\
\hline HDLMeanValDiff & -0.0698 & 0.0037 & -18.8000 & 0.0000 & -0.0771 & -0.0625 \\
\hline HDLCoeffVar & 0.0427 & 0.0017 & 24.5700 & 0.0000 & 0.0393 & 0.0461 \\
\hline Constant & -3.9803 & 0.0538 & -73.9700 & 0.0000 & -4.0857 & -3.8748 \\
\hline
\end{tabular}

$\mathrm{n}=286,325 ; \mathrm{ROC}=0.631$ 
medRxiv preprint doi: https://doi.org/10.1101/2022.01.22.22269691; this version posted February 22, 2022. The copyright holder for this preprint

(which was not certified by peer review) is the author/funder, who has granted medRxiv a license to display the preprint in perpetuity.

This article is a US Government work. It is not subject to copyright under 17 USC 105 and is also made available for use under a CCO license.

METABOLIC PROFILING AND COVID-19 DEATH

\section{REFERENCES}

1. King JT Jr, Yoon JS, Rentsch CT, et al. Development and validation of a 30-day mortality index based on pre-existing medical administrative data from 13,323 COVID-19 patients: The Veterans Health Administration COVID-19 (VACO) Index. PLoS One. 2020 Nov 11;15(11):e0241825. DOI: 10.1371/journal.pone.0241825.

2. Ioannou GN, Green P, Fan VS, et al. "Development of COVIDVax model to estimate the risk of SARS-CoV-2-related death among 7.6 million US veterans for use in vaccination prioritization," JAMA Network Open 2021; 4:e214347.

3. Barda N, Riesel D, Akriv A, et a. Developing a COVID-19 mortality risk prediction model when individual-level data are not available. Nature Communications 2020. DOI: 10.1038/s41467-020-18297-9.

4. Hippisley-Cox J, Coupland CAC, Mehta N, et al. Risk prediction of covid-19 related death and hospital admission in adults after covid-19 vaccination: national prospective cohort study. BMJ 2021;374:n2244.

5. Cohn BA, Cirillo PM, Murphy CC, et al. SARS-CoV-2 vaccine protection and deaths among US veterans during 2021. Science 2021. DOI: 10.1126/science.abm0620.

6. Murata $\mathrm{GH}$, Murata AE, Campbell HM, Mcmahon BH, Mao JT. A novel method for handling pre-existing conditions in prediction models for COVID-19 death. Medrxiv 2022. DOI:

https://doi.org/10.1101/2022.01.22.22269694 